\title{
Nosokomycins, new antibiotics discovered in an in vivo-mimic infection model using silkworm larvae. II: Structure elucidation
}

\author{
Ryuji Uchida ${ }^{1}$, Masato Iwatsuki ${ }^{2}$, Yong-Pil Kim ${ }^{2,3}$, Satoshi Ōmura ${ }^{2}$ and Hiroshi Tomoda ${ }^{1}$ \\ The structures of nosokomycins A, B, C and D, new anti-methicillin-resistant Staphylococcus aureus antibiotics produced \\ by Streptomyces sp. K04-0144, were elucidated by spectroscopic studies including various NMR experiments. Nosokomycins \\ A, B, C and D are new members of the moenomycin family consisting of an oligosaccharide moiety, a 2,3-dihydroxypropionic \\ acid and an unusual sesterterpenoid moiety. All nosokomycins lack the cyclopentenone moiety in the oligosaccharide moiety \\ of moenomycin A.
}

The Journal of Antibiotics (2010) 63, 157-163; doi:10.1038/ja.2010.10; published online 5 March 2010

Keywords: anti-methicillin-resistant S. aureus antibiotics; moenomycin family; nosokomycins; phosphoglycolipid; structure elucidation

\section{INTRODUCTION}

Our research group has focused on the discovery of anti-infectives from microbial metabolites. ${ }^{1-3}$ In the course of in vivo-mimic screening using silkworm larvae to discovery antibiotics that are active against methicillin-resistant Staphylococcus aureus, nosokomycins A, B, $\mathrm{C}$ and D (Figure 1) were isolated as active components from the culture broth of Streptomyces sp. K04-0144. ${ }^{4}$ In this study, the physicochemical properties and structure elucidation of nosokomycins are described.

\section{RESULTS}

Physico-chemical properties of nosokomycins

The physico-chemical properties of nosokomycins are summarized in Table 1. The strong IR absorption at 3400 and $1720 \mathrm{~cm}^{-1}$ suggested the presence of a hydroxyl group and a carbonyl group. In their UV spectra, nosokomycins showed no characteristic absorption other than end absorption, and no reliable peaks related to MW were observed for this series of compounds during FAB-MS measurements. Therefore, LC-ESI-MS (magnetic sector-type) was used to elucidate the MWs of nosokomycins (Table 1). The similarities in their physicochemical properties strongly suggested that they are structurally related.

\section{Structure elucidation of nosokomycin B (2)}

The first structure study was carried out for nosokomycin B (2), the major active component among them. The analysis of its ${ }^{1} \mathrm{H},{ }^{13} \mathrm{C}$ and 2D NMR spectral data indicated that 2 is a moenomycin-like phosphoglycolipid antibiotic, which consists of five substituted sugar moieties B-F, a 2,3-dihydroxypropionic acid $(\mathbf{H})$ and an unusual sesterterpenoid moiety with the formula $\mathrm{C}_{25} \mathrm{H}_{39}$ (I) in 2 (Figure 2). However, the end absorption of 2 in UV spectra showed a lack of the 2-hydroxy-5-oxo-1-cyclopenten-1-ly moiety (A) of moenomycin A, which had the charcteristic absoption. The molecular formula of 2 was determined by HR-ESI-MS to be $\mathrm{C}_{64} \mathrm{H}_{104} \mathrm{~N}_{5} \mathrm{O}_{32} \mathrm{P}$ (found $\mathrm{m} / z$ $1484.6356(\mathrm{M}-\mathrm{H})^{-}$, calcd 1484.6324) in conjunction with its NMR data (Table 2). The presence of a phosphorus atom in $\mathbf{2}$ was clarified by the observation of the ${ }^{2} J_{\mathrm{C}-\mathrm{P}}$ coupling $(4.6$ and $4.4 \mathrm{~Hz})$ and ${ }^{3} J_{\mathrm{C}-\mathrm{P}}$ couplings (9.1 and $7.2 \mathrm{~Hz}$ ) in the ${ }^{13} \mathrm{C}$ NMR spectra. The sesquiterpenoid moiety (I) was assigned as moenomycicol, the moiety of moenomycin A by COSY and HMBC analysis. The ${ }^{3} J_{\mathrm{H}-\mathrm{H}}$ coupling constants $\left(J_{1,2}=8.6 \mathrm{~Hz}, J_{2,3}=8.6 \mathrm{~Hz}, J_{3}, 4=1.4 \mathrm{~Hz}\right.$ and $\left.J_{4,5}=1.4 \mathrm{~Hz}\right)$ and the HMBC correlation between the proton signal of C-5 $\left(\delta_{\mathrm{H}} 4.05\right)$ and the primary amide carbon signal $\left(\delta_{\mathrm{C}} 173.2\right)$ proved the $\alpha$-Dglucuronamate of sugar $\mathbf{B}$. The ${ }^{3} J_{\mathrm{H}-\mathrm{H}}$ coupling constants $\left(J_{1,2}=8.5 \mathrm{~Hz}\right.$, $J_{2,3}=8.6 \mathrm{~Hz}, J_{3,4}=8.6 \mathrm{~Hz}$ and $\left.J_{4,5}=8.6 \mathrm{~Hz}\right)$ and the $\mathrm{HMBC}$ correlation between the proton signal of C-2 $\left(\delta_{\mathrm{H}} 3.82\right)$ and the acetyl methyl signal $\left(\delta_{\mathrm{H}} 2.06\right)$ and the acetyl carbonyl carbon signal $\left(\delta_{\mathrm{C}} 174.1\right)$ proved the 6 -deoxy- $N$-acetyl- $\alpha$-D-glucosamate of sugar $\mathrm{C}$. The ${ }^{3} J_{\mathrm{H}-\mathrm{H}}$ coupling constants $\left(J_{1,2}=8.6 \mathrm{~Hz}, J_{2,3}=8.6 \mathrm{~Hz}, J_{3,4}=8.6 \mathrm{~Hz}\right.$ and $J_{4,5}=$ $8.5 \mathrm{~Hz}$ ) and the HMBC correlation between the proton signal of C-2 $\left(\delta_{\mathrm{H}} 3.82\right)$ and the acetyl methyl signal $\left(\delta_{\mathrm{H}} 2.06\right)$ proved the $\alpha$-Dglucosamate of sugar $\mathbf{D}$. The ${ }^{3} J_{\mathrm{H}-\mathrm{H}}$ coupling constants $\left(J_{1,2}=8.5 \mathrm{~Hz}, J_{2,3}=\right.$ $8.5 \mathrm{~Hz}, J_{3,4}=8.6 \mathrm{~Hz}$ and $\left.J_{4,5}=8.7 \mathrm{~Hz}\right)$ and the $\mathrm{HMBC}$ correlation between the proton signal of C-2 $\left(\delta_{\mathrm{H}} 3.79\right)$ and acetyl methyl signal $\left(\delta_{\mathrm{H}} 2.00\right)$ and

\footnotetext{
${ }^{1}$ Graduate School of Pharmaceutical Sciences, Kitasato University, Tokyo, Japan and ${ }^{2}$ Kitasato Institute for Life Sciences, Kitasato University, Tokyo, Japan ${ }^{3}$ Current address: Faculty of Pharmacy, Iwaki Meisei University, 5-5-1 Chuodai lino, Iwaki City, Fukushima 970-8551, Japan. 


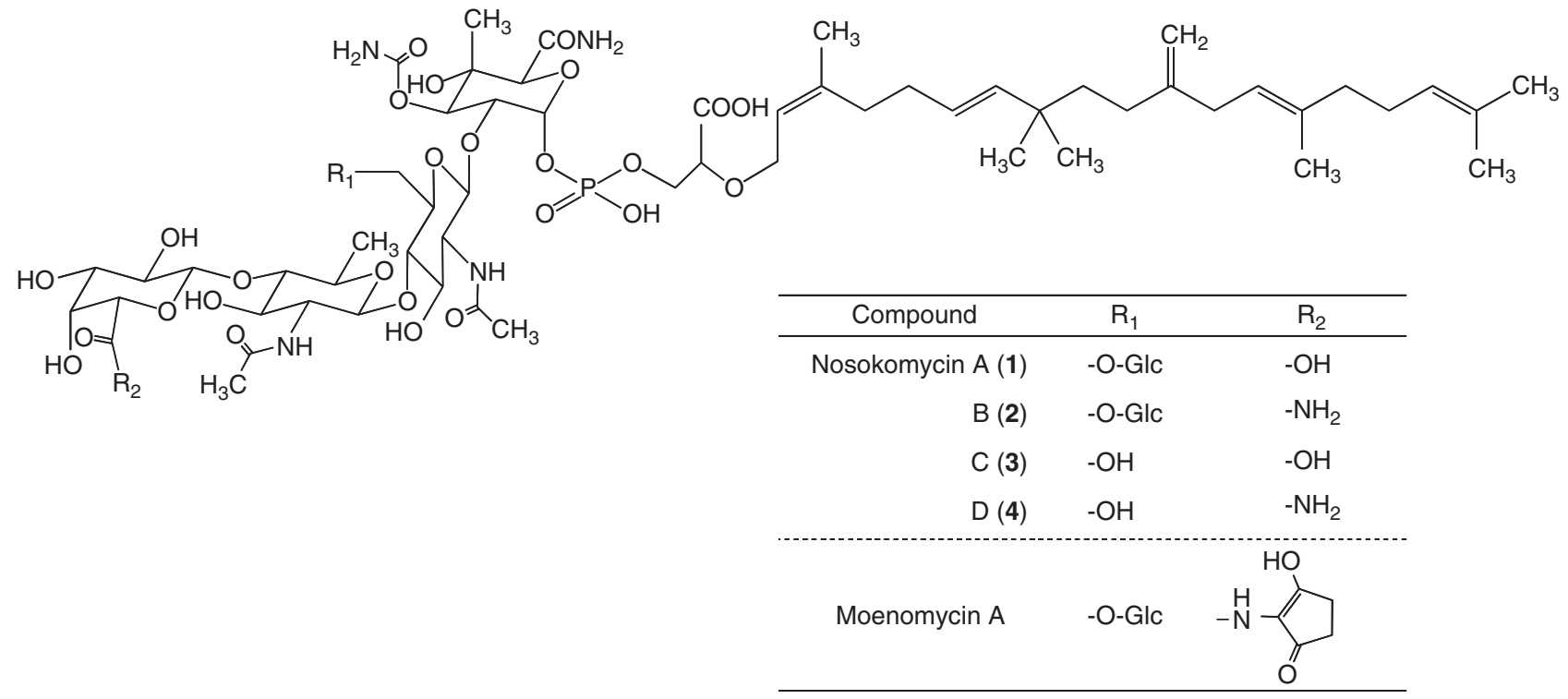

Figure 1 Structures of nosokomycins A (1), B (2), C (3) and D (4).

Table 1 Physico-chemical properties of nosokomycins A (1) to D (4)

\begin{tabular}{|c|c|c|c|c|}
\hline & 1 & 2 & 3 & 4 \\
\hline Appearance & White powder & White powder & White powder & White powder \\
\hline Molecular formula & $\mathrm{C}_{64} \mathrm{H}_{103} \mathrm{~N}_{4} \mathrm{O}_{33} \mathrm{P}$ & $\mathrm{C}_{64} \mathrm{H}_{104} \mathrm{~N}_{5} \mathrm{O}_{32} \mathrm{P}$ & $\mathrm{C}_{58} \mathrm{H}_{93} \mathrm{~N}_{4} \mathrm{O}_{28} \mathrm{P}$ & $\mathrm{C}_{58} \mathrm{H}_{94} \mathrm{~N}_{5} \mathrm{O}_{27} \mathrm{P}$ \\
\hline \multicolumn{5}{|l|}{$E S I-M S(m / z)$} \\
\hline Negative & $1485{\mathrm{[M}-\mathrm{H}]^{-}}^{-}$ & $1484[\mathrm{M}-\mathrm{H}]^{-}$ & $1323[\mathrm{M}-\mathrm{H}]^{-}$ & $1322[\mathrm{M}-\mathrm{H}]^{-}$ \\
\hline Calcd & 1485.6164 & 1484.6324 & 1323.5636 & 1322.5795 \\
\hline Found $[\mathrm{M}-\mathrm{H}]^{-}$ & 1485.6206 & 1484.6356 & 1323.5656 & 1322.5859 \\
\hline$[\alpha]_{D}^{24}(c 0.1, \mathrm{MeOH})$ & +6.7 & +5.3 & +4.0 & +3.7 \\
\hline $\mathrm{UV} \lambda_{\max }{ }^{\mathrm{MeOH}}, \mathrm{nm}(\varepsilon)$ & End absorption & End absorption & End absorption & End absorption \\
\hline IR $v_{\max }{ }^{K B r}, \mathrm{~cm}^{-1}$ & $3299,2960,1722,1673$ & $3400,2932,1675,1648$ & $3299,2923,1716,1675$ & $3400,2925,1677,1648$ \\
\hline
\end{tabular}

the acetyl carbonyl carbon signal $\left(\delta_{\mathrm{C}} 173.7\right)$ proved the $N$-acetyl- $\alpha$-Dglucosaminate of sugar E. The ${ }^{3} J_{\mathrm{H}-\mathrm{H}}$ coupling constants $\left(J_{1,2}=1.8 \mathrm{~Hz}\right.$, $\left.J_{2,3}=10.1 \mathrm{~Hz}\right)$ and the NOE correlations between the proton signals of $\mathrm{C}-2\left(\delta_{\mathrm{H}} 3.64\right)$ and the singlet methyl group $\left(\delta_{\mathrm{H}} 1.23\right)$, and the HMBC correlations between the proton signal of $\mathrm{C}-3\left(\delta_{\mathrm{H}} 5.10\right)$ and the ureido carbonyl carbon signal $\left(\delta_{\mathrm{C}} 159.2\right)$ and between the proton signal of C-5 $\left(\delta_{\mathrm{H}} 4.51\right)$ and the primary amide carbon signal $\left(\delta_{\mathrm{C}} 174.7\right)$ proved the 3-O-carbamoyl-4-methyl- $\alpha$-D-glucuronaminate of sugar $\mathbf{F}$. The connectivity of sugar moeities was determined by the correlations between the anomeric proton signals and the corresponding carbon signals (C-4 of sugar $\mathbf{C}\left(\delta_{\mathrm{H}} 4.51\right)$ and $\mathrm{C}-1$ of sugar $\mathbf{B}\left(\delta_{\mathrm{C}} 105.1\right)$, C-1 of sugar $\mathbf{C}\left(\delta_{\mathrm{H}} 4.57\right)$ and C-4 of sugar $\mathbf{E}\left(\delta_{\mathrm{C}} 82.4\right), \mathrm{C}-1$ of sugar $\mathbf{D}\left(\delta_{\mathrm{H}} 4.45\right)$ and C- 6 of sugar $\mathbf{E}$
$\left(\delta_{\mathrm{C}} 69.4\right)$, and $\mathrm{C}-1$ of sugar $\mathbf{E}\left(\delta_{\mathrm{H}} 4.51\right)$ and $\mathrm{C}-2$ of sugar $\left.\mathbf{F}\left(\delta_{\mathrm{C}} 79.7\right)\right)$ through glycoside bonds in the HMBC spectra (Figure 3 ). The mode of linkage of all sugar moieties as the $\alpha$-glycoside bond except sugar $\mathbf{F}$, was assigned by measuring the ${ }^{1} \mathrm{H}-{ }^{1} \mathrm{H}$ coupling constants of anomeric protons. The connectivity between the sesterterpenoid moiety (I) and the 2,3dihydroxypropionic acid $(\mathbf{H})$ was determined by the correlations between the proton signal of $\mathrm{C}-1$ of $\mathbf{I}\left(\delta_{\mathrm{H}} 4.22\right)$ and the carbon signal of $\mathrm{C}-2$ of $\mathbf{H}$ $\left(\delta_{\mathrm{C}} 81.2\right)$ observed in HMBC spectra (Figure 3$)$. Finally, the linkage between the $\mathrm{C}-1$ of the partial structure $\mathbf{F}$ and the $\mathrm{C}-3$ of the partial structure $\mathbf{H}$ was elucidated by the correlation from the proton signal of $\mathrm{C}$ 1 of $\mathbf{F}\left(\delta_{\mathrm{H}} 5.95\right)$ and $\mathrm{C}-3$ of $\mathbf{H}\left(\delta_{\mathrm{H}} 4.10\right)$ and the phosphorus signal of $\mathrm{P}$ of phosphate ester $\left(\delta_{\mathrm{P}-}-0.659\right)$ seen in ${ }^{1} \mathrm{H}_{-}{ }^{31} \mathrm{P}$ HMBC spectra (Figure 3$)$. 


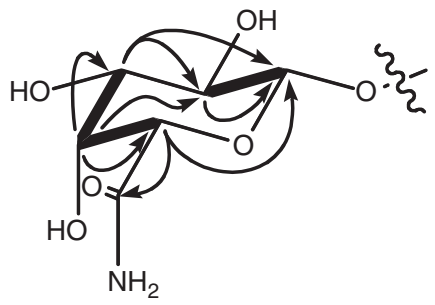

B-ring

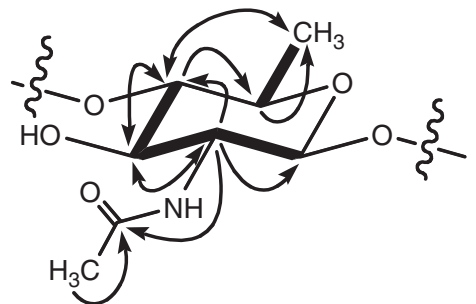

C-ring

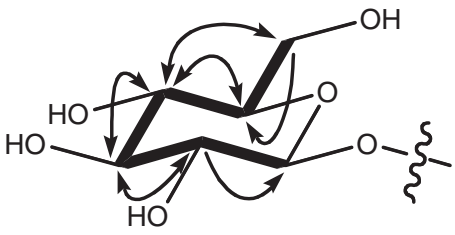

D-ring

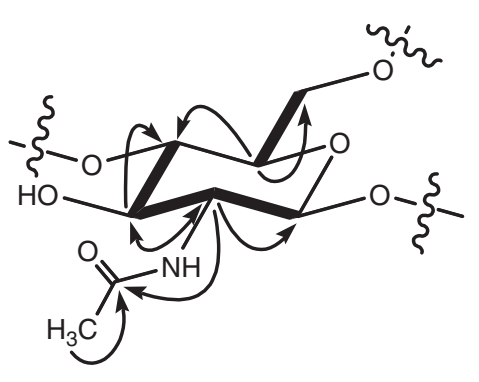

E-ring

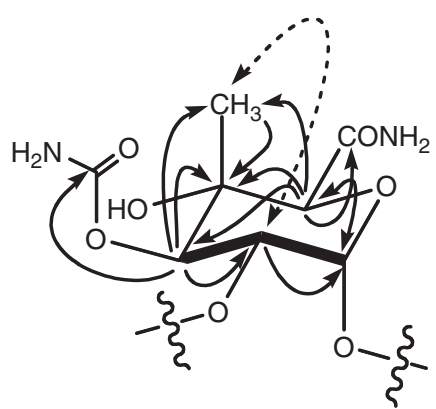

F-ring
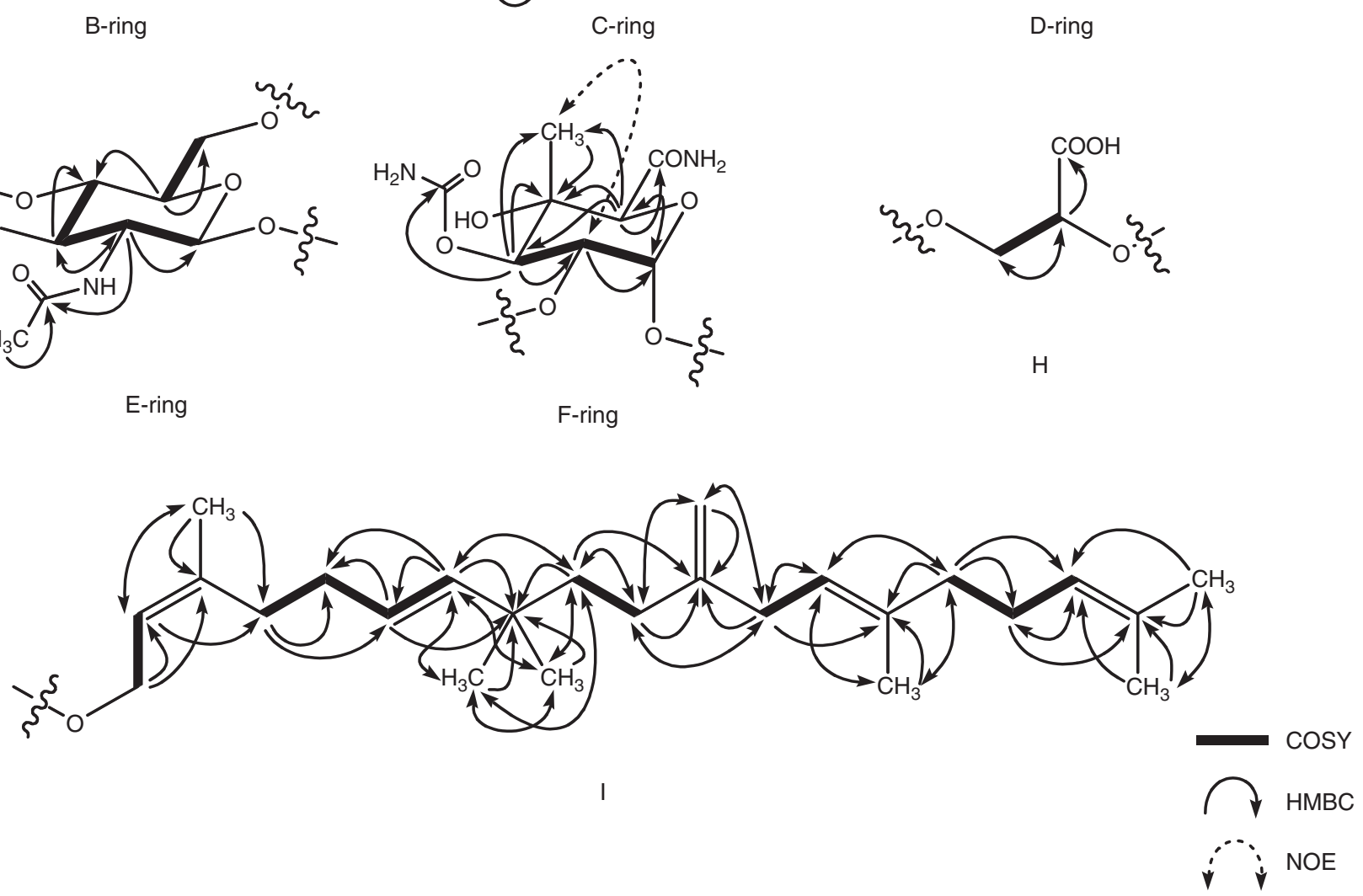

Figure 2 Partial structures of nosokomycin B (2).

From these results, the structure of $\mathbf{2}$ was elucidated as shown in Figure 1, which was a moenomycin A analog lacking moiety A. 2 was identified with the semisynthetic moenomycin derivative. ${ }^{6}$ Very recently, a biosynthetic intermediate was found by mass and $\mathrm{MS}^{2}$ fragmentation data. ${ }^{7}$

Structure elucidation of nosokomycin A (1)

The molecular formula of $\mathbf{1}$ was determined by HR-ESI-MS to be $\mathrm{C}_{64} \mathrm{H}_{103} \mathrm{~N}_{4} \mathrm{O}_{33} \mathrm{P}$ (found $\mathrm{m} / z 1485.6206(\mathrm{M}-\mathrm{H})^{-}$, calcd 1485.6164) and the results indicated the replacement of $\mathrm{NH}$ in 2 with $\mathrm{O}$ in $\mathbf{1}$. As the ${ }^{1} \mathrm{H}$ and ${ }^{13} \mathrm{C}$ NMR spectra of $\mathbf{1}$ (Table 2) resembled those of $\mathbf{2}$, it was difficult to elucidate the differences in structures by only measuring the chemical shifts among candidates (the primary amide group at C-5 in sugar $\mathbf{B}$ and at $\mathrm{C}-5$ in sugar $\mathbf{F}$ ). To observe the correlation between the proton signal at $\delta_{\mathrm{H}} 4.05(\mathrm{C}-5$ of sugar $\mathrm{B})$ and the nitrogen signal at $\delta_{\mathrm{N}} 269.4(\mathrm{~N}$ of the primary amide group of sugar $\mathbf{B}),{ }^{1} \mathrm{H}_{-}{ }^{15} \mathrm{~N}$ HMBC experiments were carried out (Figure 3). However, these correlation results were not seen on 1 , indicating that the primary amino group belonging to the C-5 of sugar $\mathbf{B}$ in $\mathbf{2}$ is replaced with a hydroxyl group in $\mathbf{1}$.

The presence of this compound in the flavomycin complex was predicted by LC-ESI-IT-MS analysis. ${ }^{8}$ Very recently, 1 was reported to be an intermediate of moenomycin biosynthesis, the structure of which was deduced by exact mass and $\mathrm{MS}^{2}$ fragmentation data. ${ }^{7}$ However, we first isolated $\mathbf{1}$ as the metabolite from the culture broth of wild-type actinomycete and obtained its full spectral data.

Structure elucidation of nosokomycin C (3)

The molecular formula of $\mathbf{3}$ was determined by HR-ESI-MS to be $\mathrm{C}_{58} \mathrm{H}_{93} \mathrm{~N}_{4} \mathrm{O}_{28} \mathrm{P}$ (found $\mathrm{m} / z 1323.5656(\mathrm{M}-\mathrm{H})^{-}$, calcd 1323.5636), indicating that 3 lacked $\mathrm{C}_{6} \mathrm{H}_{10} \mathrm{O}_{5}$ (one sugar unit) compared with $\mathbf{1}$. From a comparison of the ${ }^{1} \mathrm{H}$ and ${ }^{13} \mathrm{C}$ NMR spectra of $\mathbf{3}$ and $\mathbf{1}$ (Table 2), the signals of sugar $\mathbf{D}$ seen in $\mathbf{1}$ were absent in $\mathbf{3}$, and the chemical shift of C-6 in sugar $\mathbf{E}$ in $\mathbf{3}$ was shifted to a higher field in the ${ }^{13} \mathrm{C}$ NMR spectra $\left(\delta_{\mathrm{C}} 69.4\right.$ in $1, \delta_{\mathrm{C}} 60.8$ in 3$)$. Therefore, the structure of $\mathbf{3}$ was elucidated to be the nosokomycin A analog lacking moiety $\mathbf{D}$, as shown in Figure 1.

\section{Structure elucidation of nosokomycin D (4)}

The molecular formula of 4 was determined by HR-ESI-MS to be $\mathrm{C}_{58} \mathrm{H}_{94} \mathrm{~N}_{5} \mathrm{O}_{27} \mathrm{P}$ (found $\mathrm{m} / z 1322.5859(\mathrm{M}-\mathrm{H})^{-}$, calcd 1322.5795), which was smaller than that of 2 by $\mathrm{C}_{6} \mathrm{H}_{10} \mathrm{O}_{5}$. From a comparison of the ${ }^{1} \mathrm{H}$ and ${ }^{13} \mathrm{C}$ NMR spectra of 4 and 2 (Table 2), the signals of 


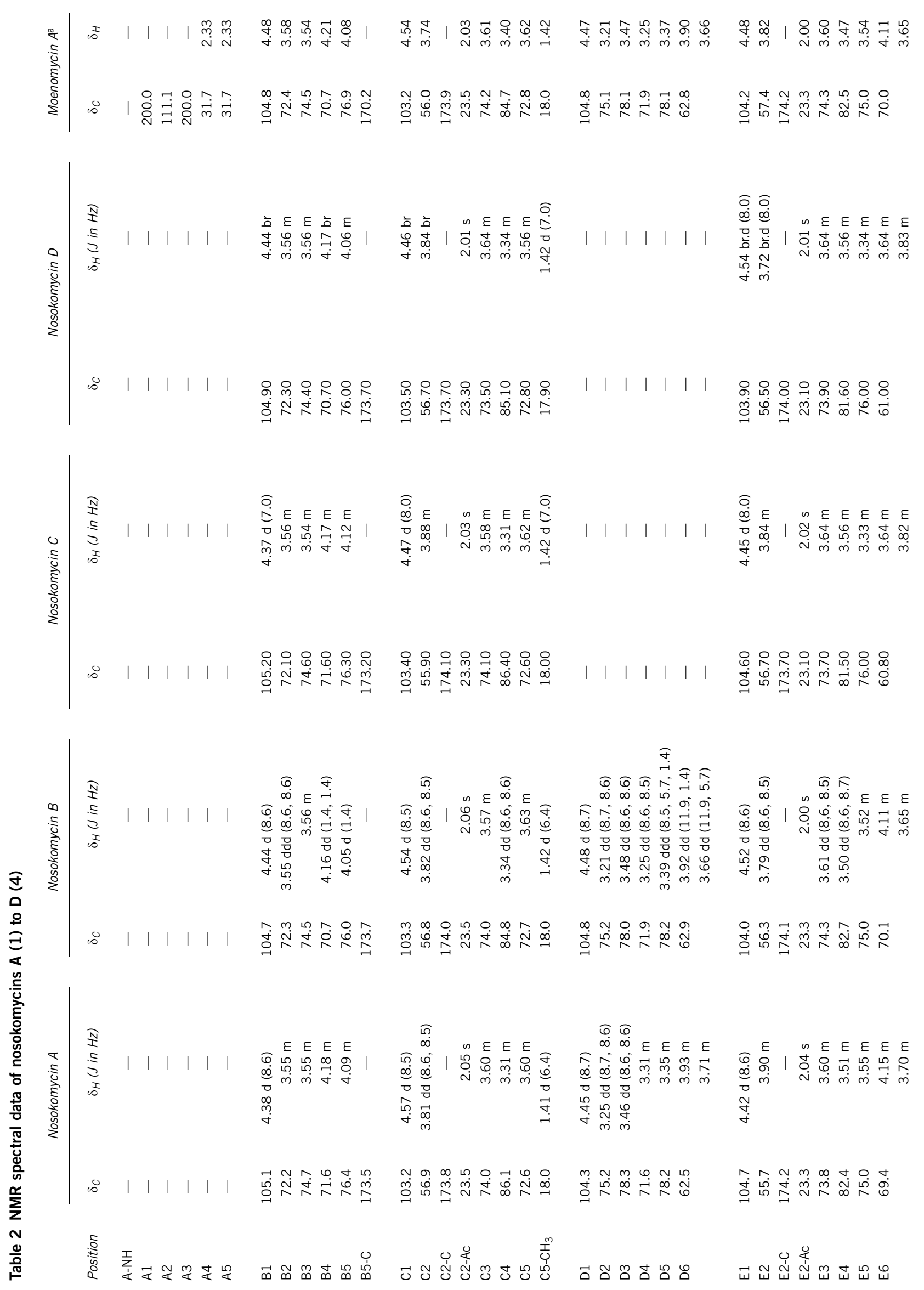




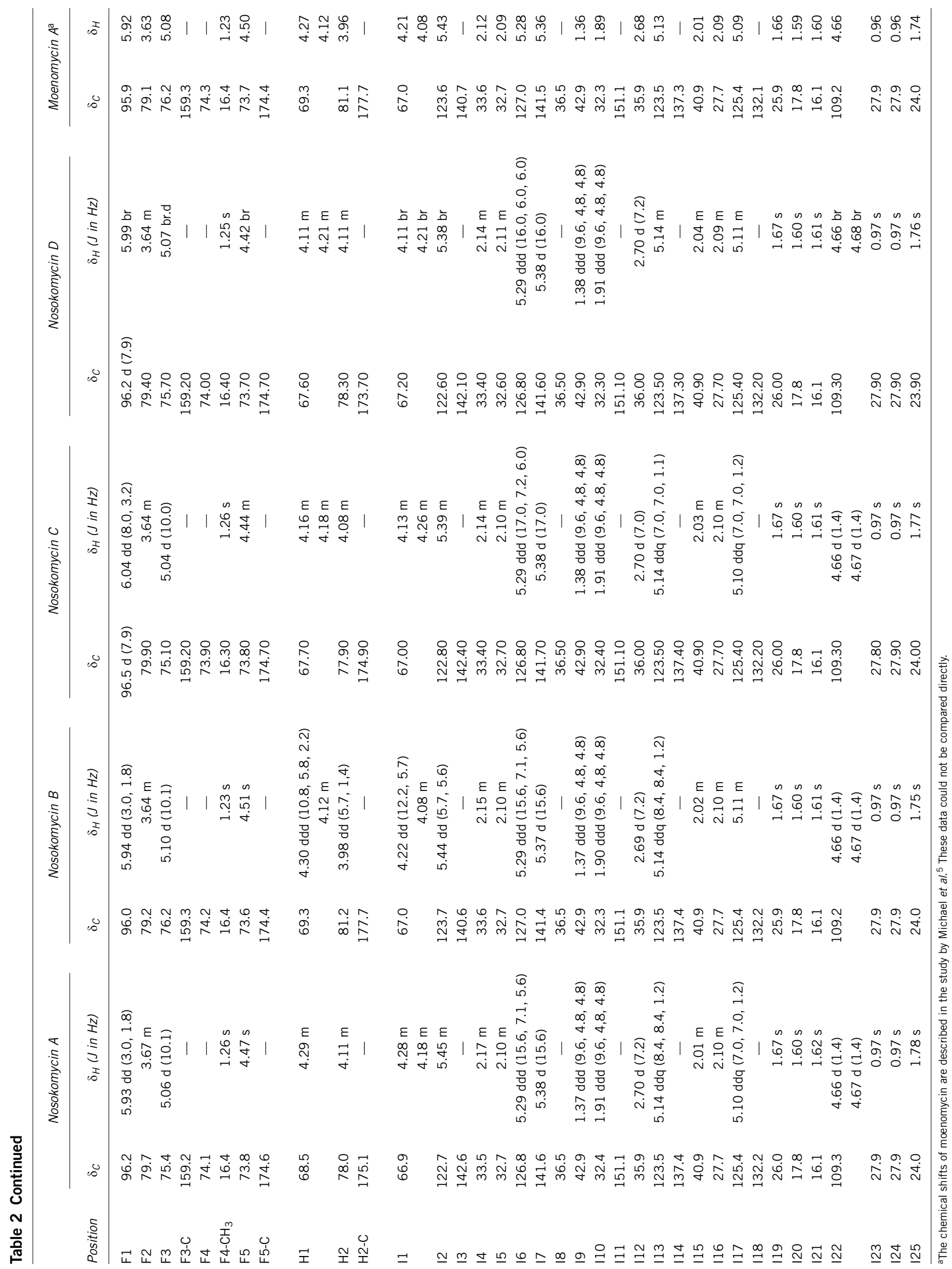




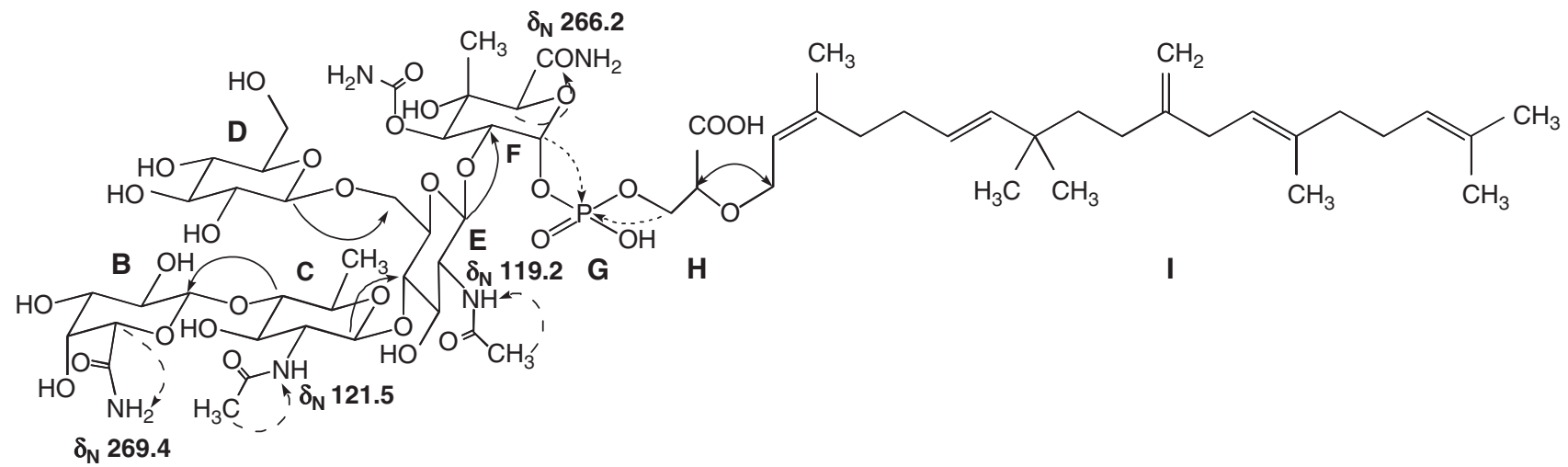

$$
\begin{aligned}
& { }^{-}{ }^{1} \mathrm{H}-{ }^{15} \mathrm{~N} \text { HMBC } \\
& { }^{1} \mathrm{H}-{ }^{13} \mathrm{C} \text { HMBC } \\
& \therefore{ }^{1} \mathrm{H}-{ }^{31} \mathrm{P} \text { HMBC }
\end{aligned}
$$

Figure 3 The linkages between the partial structures in nosokomycin B (2).

sugar $\mathbf{D}$ in $\mathbf{2}$ were found to be absent in $\mathbf{4}$, and the chemical shift of C-6 seen in sugar $\mathbf{E}$ in 4 was shifted to a higher field in ${ }^{13} \mathrm{C} N M R$ spectra $\left(\delta_{\mathrm{C}} 70.1\right.$ in $2, \delta_{\mathrm{C}} 61.0$ in 4$)$. Therefore, the structure of 4 was elucidated to be the nosokomycin B analog lacking moiety $\mathbf{D}$, as shown in Figure 1.

\section{DISCUSSION}

According to the structures of the nosokomycins elucidated in this study, they belong to the moenomycin family of antibiotics. Nosokomycin B (2), which lacks the chromophoric cyclopentenone moiety (A), was identical to the semisynthetic moenomycin A derivative. ${ }^{6}$ However, 2 was isolated as a main product from Streptomyces sp. K040144. More than 25 members of the moenomycin family have been reported from microbial metabolites. ${ }^{8}$ However, the structures of only a few members have been fully elucidated. ${ }^{5}$

From the structure-activity relationship of moenomycin derivatives reported previously, it has been found that moenomycin trisaccharides containing units C, E, F, G, H and I are the smallest cores to show antibiotic activity in vivo, ${ }^{6}$ whereas moenomycin disaccharides containing units E-I still function as transglycosylase inhibitors in vitro. ${ }^{9}$ Nosokomycins are larger than the smallest cores of in vivo-active moenomycin derivatives and are also smaller than moenomycin A itself. Therefore, it is reasonable that nosokomycins retain activity.

Recently, Walker and coworkers ${ }^{10}$ proposed a biosynthetic pathway for the cyclopentenone (A ring) moiety and the pentasaccharide section of moenomycin A using a whole-genome scanning approach with the producing strain Streptomyces ghanaensis ATCC 146723 in combination with gene knockout and complementation experiments. ${ }^{10,11}$ They described that MoeA4 functions as an acyl-CoA ligase that cyclizes aminolevulinate to form the cyclopentenone (A ring) moiety and that MoeB4 functions as an amide synthetase that couples the A ring moiety to the C- 6 of the $\mathbf{B}$ ring of moenomycin A. As described above, all nosokomycins lack the chromophoric cyclopentenone moiety, and no members of the moenomycin family were detected in the culture broth of the nosokomycin-producing strain, Streptomyces sp. K04-0144 strain. Therefore, we speculate that moeA4 and/or moeB4 genes do/does not work or lack(s) the nosokomycinproducing strain.

\section{METHODS}

\section{General experiments}

NMR spectra were measured on a Varian XL-400 spectrometer (Varian, Palo Alto, CA, USA) with ${ }^{1} \mathrm{H}$ NMR measured at $400 \mathrm{MHz}$ and ${ }^{13} \mathrm{C}$ NMR measured at $100 \mathrm{MHz}$ in methanol- $d_{4}$. Chemical shifts are expressed in $\delta$ values (p.p.m.) with methanol- $d_{4}\left(\delta_{\mathrm{c}} 49.0\right)$ used as an internal reference for ${ }^{13} \mathrm{C}$ NMR spectra and methanol- $d_{4}\left(\delta_{\mathrm{H}} 3.30\right)$ used an internal reference for ${ }^{1} \mathrm{H}$ NMR spectra. IR spectra were measured on a Horiba FT IR-710 spectrometer (Horiba, Kyoto, Japan), and UV spectra were measured on a Beckman DU-640 spectrophotometer (Beckman Coulter, Fullerton, CA, USA). Optical rotation was measured on a JASCO DIP-370 digital polarimeter (JASCO, Hachioji, Japan).

\section{LC-ESI-MS experiments}

LC-ESI-MS spectra were measured on a JEOL JMS-700 magnetic sector-type mass spectrometer (JEOL, Akishima, Japan) coupled with an Agilent 1100 G1310A liquid chromatography pump (Agilent Technologies, Santa Clara, CA, USA). ${ }^{12}$ The LC conditions were as follows: column, PEGASIL ODS $(2.0 \varnothing \times 50 \mathrm{~mm}$, Senshu Scientific, Tokyo, Japan); mobile phase, $\mathrm{MeOH}$; and flow rate, $0.2 \mathrm{ml} \mathrm{min}^{-1}$. The ESI source was operated in negative ion mode with a ring voltage of $100 \mathrm{~V}$. The standard substance YOKUDELNA (JEOL) was used for mass calibration with a scan range of $m / z$ 100-2000.

\section{${ }^{31} \mathrm{P}$ NMR and ${ }^{1} \mathrm{H}_{-}{ }^{31} \mathrm{P}$ HMBC experiments}

${ }^{31} \mathrm{P}$ NMR spectra were measured on a Mercury-300 spectrometer (Varian) at $300 \mathrm{MHz}$ in methanol- $d_{4}$ at room temperature. Chemical shifts are expressed in $\delta$ values (p.p.m.), and triphenylphospine $\left(\delta_{\mathrm{P}} 0.0\right)$ was used as an internal reference. ${ }^{1} \mathrm{H}-{ }^{31} \mathrm{P}$ HMBC spectra were measured under following conditions: sample $10 \mathrm{mg}, f_{1} \times f_{2}=2048 \times 512$ points, $\mathrm{nt}=16, \mathrm{ni}=160$. The pulse sequence was described in a previous study. 13

\section{${ }^{1} \mathrm{H}_{-}{ }^{15} \mathrm{~N}$ HMBC experiments}

${ }^{15} \mathrm{~N}$ NMR spectra were measured on a Varian Mercury-300 spectrometer at $300 \mathrm{MHz}$ in methanol- $d_{4}$ at room temperature. Chemical shifts are expressed in $\delta$ values (p.p.m.) and benzamide $\left(\delta_{\mathrm{N}} 105.4\right)$ was used as an internal reference. ${ }^{1} \mathrm{H}_{-}{ }^{15} \mathrm{~N}$ HMBC spectra were measured under the following conditions: sample $10 \mathrm{mg}, f_{1} \times f_{2}=2048 \times 2048$ points, $\mathrm{nt}=4000, \mathrm{ni}=90$. The pulse sequence was described in a previous paper. ${ }^{14}$

\section{ACKNOWLEDGEMENTS}

We are grateful to Ms Chigako Sakabe, Ms Akiko Nakagaw, Ms Noriko Sato and Mr Satoshi Ohte from the School of Pharmacy, Kitasato University for measuring the mass and NMR spectra and their concerted efforts in aiding this 
study. This study was supported in part by a Grant-in Aid for Scientific Research 21310146 (to HT) from the Ministry of Education, Culture, Sports, Science, and Technology of Japan and by a grant from the Uehara Memorial Foundation of Japan (to HT).

1 Fukuda, T., Matsumoto, A., Takahashi, Y., Tomoda, H. \& Ōmura, S. Phenatic acids A and B, new potentiators of antifungal miconazole activity produced by Streptomyces sp. K03-0132. J. Antibiot. 58, 252-259 (2005).

2 Koyama, N. et al. Stemphones, novel potentiator of imipenem activity against methicillin resitant Staphylococcus aureus, produced by Aspergillus sp. FKI-2136. J. Antibiot. 58, 695-703 (2005).

3 Iwatsuki, M. et al. Lariatins, novel anti-mycobacterial peptides with a lasso structure, produced by Rhodococcus jostii K01-B0171. J. Antibiot. 60, 357-363 (2007).

4 Uchida, R. et al. Nosokomycins, new antibiotics discovered in an in vivo-mimic infection model using silkworm larvae. I. Fermentation, isolation and biological properties. J. Antibiot. 63, 151-155 (2010).

5 Michael, K., Wolfgang, G. \& Laszlo, V. Three-dimensional structure of moenomucon A, a potent inhibitor of penicillin-binding protein 1b. Eur. J. Biochem. 252, 500-507 (1998).
6 Marzan, S. et al. Moenomycin A: reactions at the lipid part. New structure-activity relations. Tetrahedron 50, 5299-5308 (1994).

7 Zehl, M., Pittenauer, E., Rizzi, A. \& Allmaier, G. Characterization of moenomycin antibiotic complex by multistage MALD-IT/TOF-MS and ESI-IT-MS. J. Am. Soc. Mass Spectrum. 17, 1081-1090 (2006).

8 Arai, M. et al. Pholipomycin, a new member of phosphoglycolipid antibiotics II. physico-chemical properties and comparison with other members of this family of antibiotics. J. Antibiot. 12, 1055-1059 (1977).

9 Baizman, E. R. et al. Antibacterial activity of synthetic analogues based on the disaccharide structure of moenomycin, an inhibitor of bacterial transglycosylase. Microbiology 146, 3129-3140 (2000).

10 Ostash, B., Saghatelian, A. \& Walker, S. A streamlined metabolic pathway for the biosynthesis of moenomycin A. Chem. Biol. 14, 257-267 (2007).

11 Ostash, B. et al. Complete characterization of the seventeen step moenomycin biosynthetic pathway. Biochemistry 48, 8830-8841 (2009).

12 Sakabe, C., Iwatsuki, M., Sakayanagi, M. \& Hara, R. The abstract of 'Kikibunsekigijutsukenkyuukai'. P-13-A (2005).

13 Dominika, D. et al. Structure of the O-specific polysaccharide of Proteus penneri 103 containing ribitol and 2-aminoethanol phosphates. Carbohydrate Res. 337, 1535-1540 (2002).

14 Gary, E. M. \& Chad, E. H. Long-range ${ }^{1} \mathrm{H}-15 \mathrm{~N}$ heteronuclear shift correlation at natural abundance. J. Nat. Prod. 63, 543-585 (2000). 